\title{
The Wetting Behavior of Fresh and Aged Soot Studied through Contact Angle Measurements
}

\author{
Yiyi Wei, Qing Zhang, Jonathan E. Thompson \\ Department of Chemistry \& Biochemistry, Texas Tech University, Lubbock, TX, USA \\ Email: jon.thompson@ttu.edu
}

How to cite this paper: Wei, Y.Y., Zhang, Q. and Thompson, J.E. (2017) The Wetting Behavior of Fresh and Aged Soot Studied through Contact Angle Measurements. Atmospheric and Climate Sciences, 7, 11-22. http://dx.doi.org/10.4236/acs.2017.71002

Received: October 7, 2016

Accepted: December 4, 2016

Published: December 7, 2016

Copyright $\odot 2017$ by authors and Scientific Research Publishing Inc. This work is licensed under the Creative Commons Attribution International License (CC BY 4.0).

http://creativecommons.org/licenses/by/4.0/ (c) (i) Open Access

\begin{abstract}
In this work, contact angle measurements for soot samples collected from a kerosene lantern, wood-burning fireplace, and municipal bus engine exhaust lines are reported. Contact angles for both freshly collected soot and samples treated with various doses of $\mathrm{O}_{3}(\mathrm{~g}), \mathrm{HNO}_{3}(\mathrm{~g})$, and $\mathrm{H}_{2} \mathrm{SO}_{4}(\mathrm{~g})$ are considered. Use of a literature method has allowed estimation of the enthalpy of immersion $\left(H_{\text {imm }}\right)$ for the soot samples based on contact angle observed. Contact angles for freshly collected soot were 65 - 110 deg. indicating its hydrophobic nature. Chemical processing of soot usually resulted in smaller contact angles and large increases in immersion enthalpy. However, the dose of ozone, nitric or sulfuric acid vapor required to achieve alteration of the soot surface appeared to be considerably larger than that expected to be experienced by authentic atmospheric samples during the soot particles lifetime. The most significant variability of soot contact angle was observed for the municipal bus exhaust samples, suggesting that combustion chemistry may significantly affect wetting behavior.
\end{abstract}

\section{Keywords}

Soot, Black Carbon, Wetting, Enthalpy of Immersion, Contact Angle, Graphene Oxide

\section{Introduction}

Atmospheric nanosphere soot (ns-soot) a.k.a. refractory black carbon $(\mathrm{rBC})$ is formed during incomplete combustion. Soot is frequently composed of grape-like aggregates of primary particles (approx. 20 - $50 \mathrm{~nm}$ diameter) linked together to form long chains that can reach several micrometers in length. Soot primary particles can be thought of as a mixture of $\mathrm{sp}^{3}$ hybridized carbon combined with highly strained graphitic $\mathrm{sp}^{2}$ layers required to conform to the spherical geometry of particles. The $\mathrm{sp}^{2}$ graphitic layers or islands are responsible for the strong light absorbing properties of soot and are quite stable to chemical attack. While soot particles are insoluble in most solvents (including 
water) we have become interested in understanding how atmospheric soot particles behave within or on the surface of micrometer-sized droplets of solvent. The essential question is whether soot particles fully immerse within liquid droplets, or remain on the surface of the liquid. Such details are crucial for developing a better understanding of the chemistry of the droplets, and for understanding the environmental impacts of light absorption by soot in Earth's atmosphere.

Existing literature portrays a mixed picture. Chylek and Hallet [1] report soot produced from acetylene combustion remains partially submerged at the surface of aqueous droplets for many hours. Popovicheva et al. [2] report photographs depicting soot at the droplet surface for certain types of soot, but immersion occurring for soot from alternate sources. Recent field measurements of light absorption by soot at high relative humidity best agree with the immersion model on average, however, the authors also reported periods of time during which data was inconsistent with immersion occurring [3].

Towards the goal of fully understanding the interaction of soot with water droplets, we have studied the water contact angle of pelletized soot measured via the sessile drop approach. In addition to untreated samples, the soot has been subjected to simulated chemical aging within a laboratory in an attempt to alter surface chemistry and wetting behavior. Enthalpy of immersion $\left(H_{\text {imm }} ; \mathrm{mJ} / \mathrm{cm}^{2}\right)$ values have been estimated through the approach outlined in Spagnolo et al. [4]. These authors derived an equation to relate contact angle $(\theta)$ to heat of immersion:

$$
\cos \theta=\frac{-0.07 T-H_{i m m}}{\gamma_{l v}}
$$

In this equation, $T$ is the Kelvin temperature, $H_{i m m}$ is the immersion enthalpy and $\gamma_{I v}$ is the liquid-vapor surface tension.

Despite being widely recognized as a hydrophobic surface, calorimetry experiments consistently suggest the immersion of soot or carbon blacks in water is an exothermic process often yielding $30-90 \mathrm{~mJ}$ per $\mathrm{m}^{2}$ of surface area. Several authors have reported an approximate linear relationship between BC surface oxygen content and immersion enthalpy [5] [6] [7]. As early as 1954, Young et al. determined that graphon (graphitic material with extremely low surface oxygen content) has a heat of immersion in water of approx. $32 \mathrm{~mJ} / \mathrm{m}^{2}$ [8]. Kraus extended upon this work by reporting heats of immersion for a variety of carbon blacks with differing surface density of $\mathrm{O}$ atoms [6]. Kraus also observed an approx. linear trend between $\mathrm{O}$ atom surface density and heat of immersion in the polar solvents water and methanol. Kraus remarked that the observed range in heat of immersion values is approx. $30-80 \mathrm{~mJ} / \mathrm{m}^{2}$ for carbon blacks as they transform from near zero oxygen coverage to a fully oxygenated surface. Similar linear trends have been reported in more recent literature by Rodriguez-Reinoso et al. [7] and Bradley et al. [5].

A similar chemical transformation has recently been studied intensely within nanomaterials research. Many papers report on the conversion of graphene to "graphene oxide" through chemical oxidation. The proposed structure for graphene oxide is drawn in Figure 1 (fig. courtesy of Sigma-Aldrich). Graphene oxide features oxygen atoms incorporated onto the carbon sheet as either alcohols or epoxides. On the edges of the 


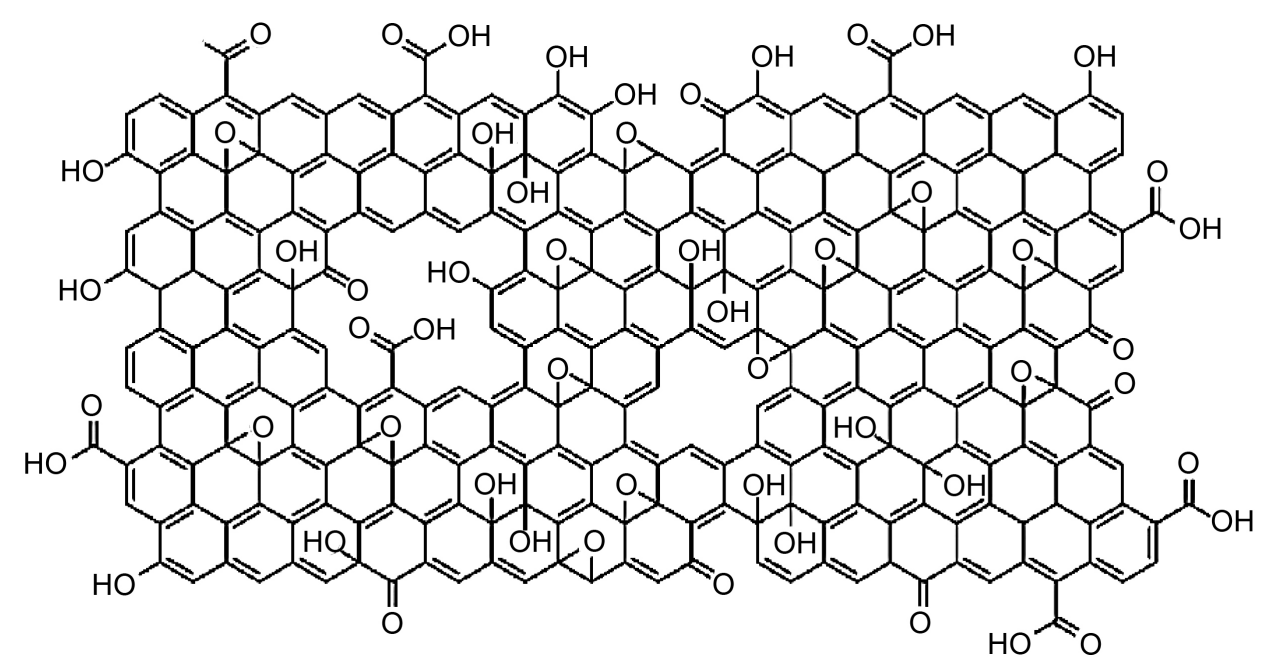

Figure 1. A possible structure of graphene oxide, a potential model for oxidized soot surfaces. The graphitic $\mathrm{sp}^{2}$ hybridization is disrupted by formation of alcohol and epoxide groups on the planar surface. Carboxylic acid groups are believed to form at the periphery or at defect sites. Figure courtesy of Sigma Aldrich.

graphene, or at lattice defects, carboxylic acid group are thought to be present. Such transformation is important within the nanotechnology field since graphene oxide is considered water-soluble (although dispersible may be better terminology). Wang et al. [9] have reported the water contact angles of $98.3^{\circ}, 127^{\circ}$ and $67.4^{\circ}$ for graphite, graphene, and graphene oxide, respectively. This indicates more favorable interactions for the surface functionalized graphene oxide in water. Consequently, the graphene-graphene oxide transformation represents a potential model system for atmospheric soot chemical aging and surface modification through exposure to oxidants. It is known that the surface of graphene can be modified by treatment with $\mathrm{O}_{3}(\mathrm{~g}), \mathrm{HNO}_{3}(\mathrm{~g})$, or $\mathrm{H}_{2} \mathrm{SO}_{4}$ (g) [10]. Liu et al. [11] found that the surface of a soot surrogate (Printex $\mathrm{U}$ ) exhibited Raman spectra indicative of $\mathrm{C}=\mathrm{O}$ group formation within approx. $30 \mathrm{~min}$ of ozone treatment at $80 \mathrm{ppm}$ (corresponds to approx. 144,000 ppm sec dose). This dose of ozone far exceeds what would typically be expected for soot in Earth's atmosphere (approx. dose of 2000 - $5000 \mathrm{ppm}$ sec per day), but nonetheless the experimental result suggests soot surface chemistry may be modified in the atmosphere by ozone. Such heterogeneous phase reactions may oxidize the soot surface and increase the ability of soot to immerse into atmospheric liquid phases. As such, reporting contact angle and immersion enthalpy data as a function of oxidative dose is a worthwhile goal.

\section{Methods}

\subsection{Soot Samples}

We have analyzed several different soot samples. Kerosene lamp soot was produced by burning Coleman fuel in a wicked lantern (Walmart). Soot produced by this technique is known to be largely uncoated and composed of primary particles of approx. $40 \mathrm{~nm}$ diameter [12]. We also obtained soot from the chimney of a residential wood-burning fireplace (here called fireplace soot). This soot sample was scraped from the chimney wall, and collected into a small plastic vial for analysis. Diesel soot samples were col- 
lected from the tailpipe of active municipal buses in Lubbock, TX (Citibus). All buses burn the same fuel (low sulfur \#2), but have different engines and manufacturers. One sample was collected from a 2006 Gillig Cummins Diesel using a plastic brush. A second sample was scraped from tail pipe of a 2001 Nova Cummins Diesel by a metal scraper. A third sample was scraped from the tail pipe of a 2000 RTS Detroit Diesel bus. A fourth sample was removed from a metal diesel particulate filter. The soot on this filter was produced from burning low sulfur \#85 Diesel. After collection, the samples were filtered through a $250 \mu \mathrm{m}$ sieve to remove any large debris. Each sample was stored in a small plastic bottle (under air) until analysis.

\subsection{The Preparation and Chemical Treatment of Soot Samples}

Soot pellets were prepared by manually compressing a small amount of a soot sample between sheets of aluminum foil prior to exposure with reactive gases. All experiments were carried out at laboratory pressure $(0.91 \mathrm{~atm})$ and temperature $(295 \mathrm{~K})$.

Soot samples were exposed to ozone within a $3.6 \mathrm{~m}^{3}$ chamber lined with FEP. Ozone was produced from zero air (flow rate is $2.25 \mathrm{~L} / \mathrm{min}$ ) using a photolytic ozone generator, and then added to the chamber. Meanwhile, filtered air at a flow rate of $1 \mathrm{~L} / \mathrm{min}$ was also added into the chamber to dilute and circulate/mix the ozone. The concentration of ozone was monitored with a $2 \mathrm{~B}$ Technologies ozone sensor. The soot pellets were placed into the chamber when the ozone concentration reached $5000 \mathrm{ppbv}$, and the concentration of ozone was recorded every 10 minutes to determine the dose experienced by the soot pellet. The concentration of ozone typically increased during the experiment and reached levels as high as 14,000 ppbv. The soot samples were not directly illuminated during the experiment. Dose of ozone, nitric acid, and sulfuric acid vapor (ppm sec) were calculated by multiplying exposure time (sec) by observed concentrations (ppm).

In a separate set of experiments, pelletized soot samples were exposed to $\mathrm{HNO}_{3}(\mathrm{~g})$ within a glass dessicator placed within a fume hood. Nitric acid vapor was produced from outgassing of a few $\mathrm{mL}$ volume of a concentrated $68 \%-70 \% \mathrm{w} / \mathrm{w}$ solution of nitric acid also placed within the dessicator. The dessicator lid was left slightly ajar to allow a capillary sample inlet tube for a residual gas analyzer (RGA) to enter the dessicator. The concentration of vapor phase $\mathrm{HNO}_{3}$ was estimated through use of a residual gas analyzer (RGA, Extorr Inc.). This was accomplished by monitoring the peak for $\mathrm{NO}_{2}^{+}$at $\mathrm{m} / \mathrm{z}=46$. This peak has previously been observed as the base peak for the electron impact spectrum of $\mathrm{HNO}_{3}$ [13] and is believed to result from fragmentation $\left(\mathrm{HNO}_{3} \rightarrow \mathrm{OH}+\mathrm{NO}_{2}\right)$ in the source. We then ratio the $\mathrm{m} / \mathrm{z}=46$ peak to that observed by the RGA for molecular oxygen at $\mathrm{m} / \mathrm{z}=32$ and correct for oxygen's fractional abundance (e.g. $20 \% \mathrm{v} / \mathrm{v}$ ) to report a concentration of $\mathrm{HNO}_{3}$ in ppm units. Typical indicated concentrations were in the $5-70 \mathrm{ppm}$ range. The indicated concentrations were much lower than the equilibrium vapor pressure of 2 - $4 \mathrm{~mm} \mathrm{Hg}$ (approx. 2 - 5 ppth) reported by Taylor [14] for a $70 \% \mathrm{HNO}_{3}$ solution at room temperature. This discrepancy likely results from several factors including the lack of equilibration between liquid/gas phases due to dessicator lid being slightly open and adsorption of nitric acid to surfaces. $\mathrm{NO}_{2}(\mathrm{~g})$ would represent an isobaric interference with the peak at $\mathrm{m} / \mathrm{z}=46$ so 
the concentrations of $\mathrm{HNO}_{3}$ reported within are subject to uncertainty. Given the $\mathrm{HNO}_{3}$ vapor pressure is roughly 100 - 1000× greater than measured, if error does exist, the $\mathrm{HNO}_{3}$ dose administered to the soot samples may be higher than what has been reported within this work.

A third set of conditions exposed soot pellets to sulfuric acid vapor within a sealed glass dessicator. Briefly, a $96 \% \mathrm{wt} / \mathrm{wt}$ sulfuric acid solution was placed in the bottom of the dessicator and the soot pellet was placed within the head-space of the solution such that the soot was only exposed to the vapor. The dessicator was sealed, and the vapor-liquid equilibrium condition was sought over $3 \mathrm{~h}$ periods of time. At each $3 \mathrm{~h}$ time increment, the water contact angle was measured. Sulfuric acid is far less volatile than nitric acid (sat. vapor pressure of $1.8 \times 10^{-8}$ bar or $17.7 \mathrm{ppbv}$ ) [15] and the concentration could not be directly measured by techniques available in our laboratory. Instead, we use the saturation vapor pressure for estimating dose of $\mathrm{H}_{2} \mathrm{SO}_{4}(\mathrm{~g}$ ) vapor applied to soot samples. Since, the dessicator seal was broken every 3 hours to remove samples for analysis it is likely our reported doses are slightly high since the vapor would be diluted with room air when the seal is broken, and some amount of time would be needed to reestablish phase equilibrium. As a result, the sulfuric acid vapor doses reported within are also subject to significant uncertainty.

\subsection{The Measurement of Contact Angle}

Soot pellets were placed on the surface of a small aluminum cube and a drop of water was carefully added onto the surface of the soot pellet. Then, photographs of the soot surface and drop were quickly acquired with a digital camera (Panasonic, DMC-FX 48) mounted on a tripod. Only the initial contact angle was reported. Image $J$ freeware (http://rsb.info.nih.gov/ij/index.html) was used to determine contact angle (angle can be directly read from this software). Enthalpy of immersion for each soot sample was then computed using Equation (1).

\section{Results and Discussion}

\subsection{Contact Angle and Wetting of Soot Untreated Samples}

Figure 2(b) illustrates a photograph of a water drop on a soot pellet, and the resulting contact angle. Figure 2(a) reports initial contact angle data and immersion enthalpy data for several soot samples tested and comparison data from previous literature [16]. The samples tested exhibited a variety of initial contact angles. Both kerosene soot and fireplace soot always exhibited initial contact angles near $100^{\circ}$. However, the diesel engine soot samples were far more diverse yielding contact angles from $>100^{\circ}$ to approx. $65^{\circ}$. This is particularly interesting because three of the four samples were obtained from engines that burn identical fuel.

The range of contact angles observed is very similar to values Persiantseva et al. reported in 2004 for several different soot samples [16]. Four of the six samples tested exhibited contact angles similar to graphite.

The American Society for Testing and Materials (ASTM) standard ASTM D733408 (2013) defines several classes for materials based on water contact angle exhibited. 


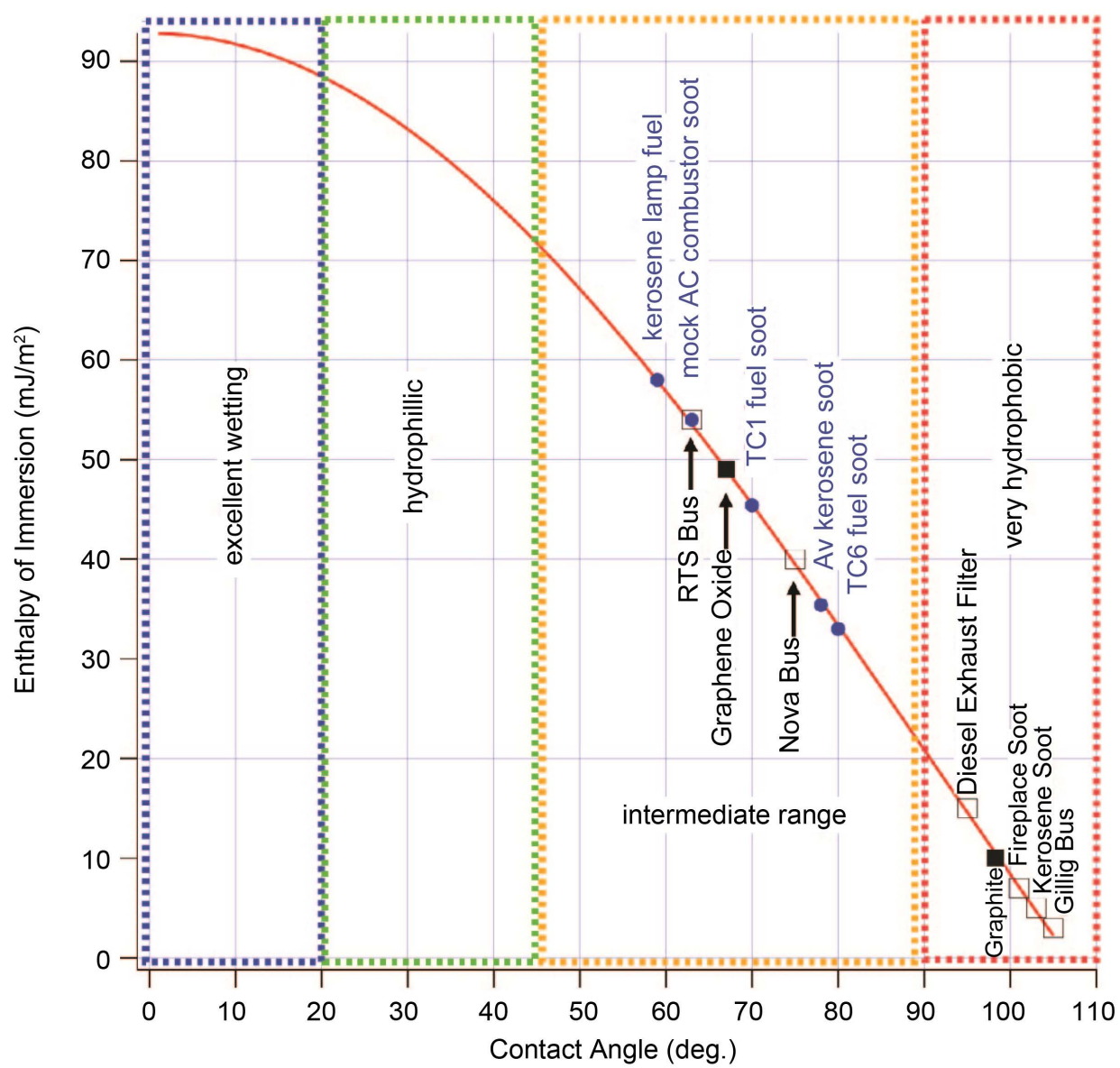

(a)
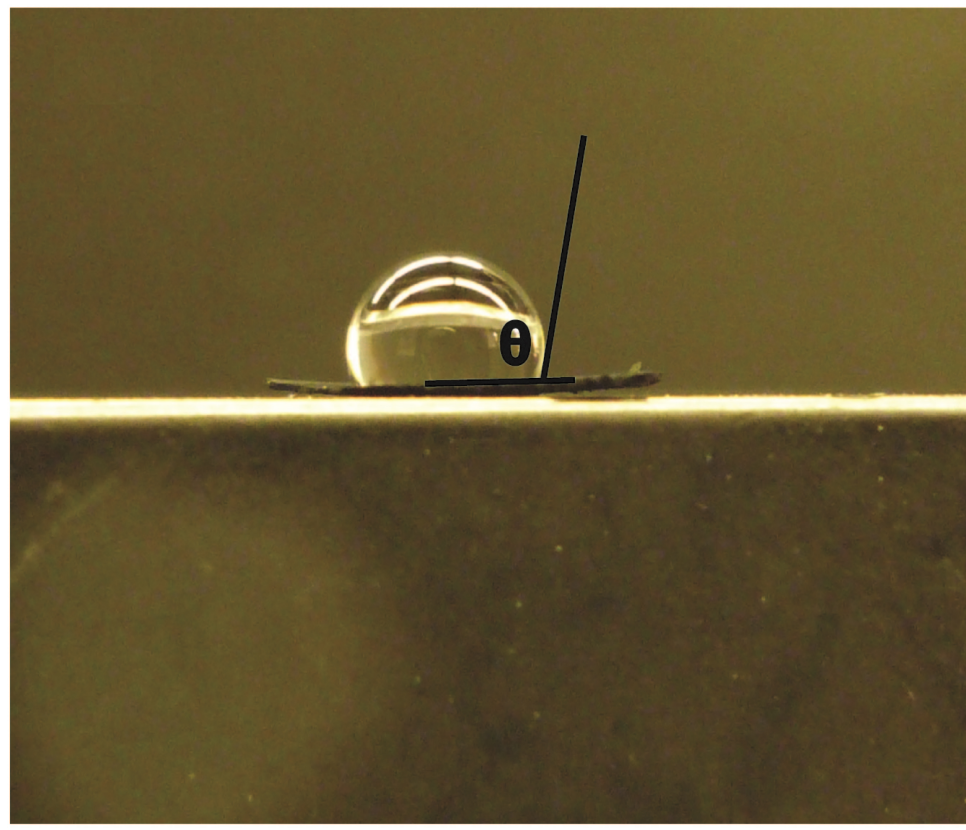

(b)

Figure 2. (a) Plot of immersion enthalpy vs. water contact angle for several test soots, graphite, and graphene oxide. Data points indicated by $(\bullet)$ are from Persiantseva et al. [16] and data points indicated by (ם) are from Wang et al. [18]. Immersion enthalpies are estimated through Equation (1). (b) Photograph of water drop on soot pellet with contact angle defined. 
Materials exhibiting contact angles $<20^{\circ}$ have excellent wetting properties, contact angles $<45^{\circ}$ indicate hydrophilic surfaces. Contact angles between $45^{\circ}-90^{\circ}$ are of intermediate range as materials transition from mostly hydrophilic to hydrophobic. A contact angle of $90^{\circ}$ or greater indicates a hydrophobic surface. All soot samples tested without further chemical treatment fell within either the hydrophobic or intermediate range. Corresponding enthalpy of immersion values ranged from $5-54 \mathrm{~mJ} / \mathrm{m}^{2}$. The very large range of contact angles observed for the different bus samples suggests the wetting behavior of soot may be heavily influenced by the source of emission.

\subsection{Contact Angles for Soot Treated with Ozone}

Figure 3 reports contact angle and $H_{\text {imm }}$ data for all soot samples as a function of the extent of ozone treatment. As observed, most samples exhibited a decrease in contact angle (and corresponding increase in $H_{i m m}$ ) when treated with large doses of ozone. The only exception to this trend was the diesel soot from a Gillig bus. This sample exhibited a slight initial decrease in contact angle, but as the ozone dose increased the trend reversed and the final contact angle was even larger than the initial value. The cause of this result is not clear. However, after extensive treatment with ozone many of the soot
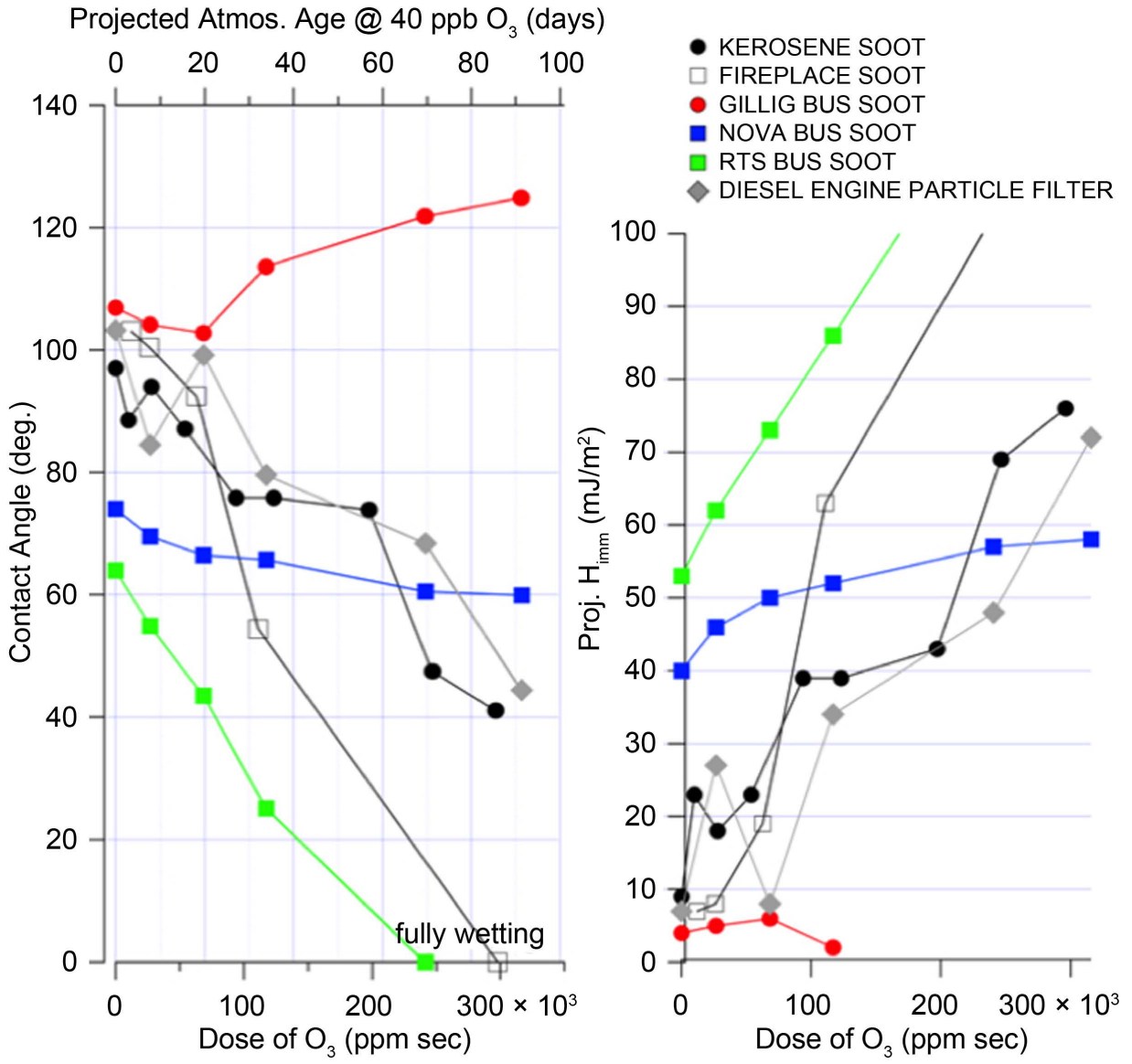

Figure 3. Plots of contact angle and projected $H_{\text {imm }}$ vs. dose of ozone applied for several soot samples. Immersion enthalpy was determined through Equation (1). Contact angles often decreased during ozone treatment and $H_{\text {imm }}$ values increased. Results suggest large doses of ozone make soot surfaces more hydrophilic. 
pellets became hydrophilic and exhibited contact angles $<45^{\circ}$. Two soot samples did not support formation of a droplet (full wetting) after ozone treatment. These observations are largely consistent with the hypothesis that soot surface modifications can drive surface wetting. We note that the dose of ozone used in these experiments was generally far in excess of what might typically be encountered in the atmosphere. A second $\mathrm{x}$-axis has been added to Figure 3 that lists the projected atmospheric aging time required to achieve the dose used in the experiment assuming a typical daylight tropospheric concentration of ozone $(40 \mathrm{ppb})$. Since a typical soot particle may have an atmospheric residence time of $<10$ days, and diurnal mean $\mathrm{O}_{3}$ concentration will likely be less than $40 \mathrm{ppbv}$, it is unclear whether the action of gas-phase ozone is sufficient to extensively modify the soot surface and dramatically affect wetting during a soot particles atmospheric lifetime.

\subsection{Contact Angles for Soot Treated with Nitric Acid Vapor}

A similar set of experiments has also been carried out in which soot pellets were treated with gas-phase $\mathrm{HNO}_{3}$ produced from the headspace vapors of a ca. 70\% solution of nitric acid. Figure 4 reports contact angle and $H_{\text {imm }}$ data for the soot samples as a function

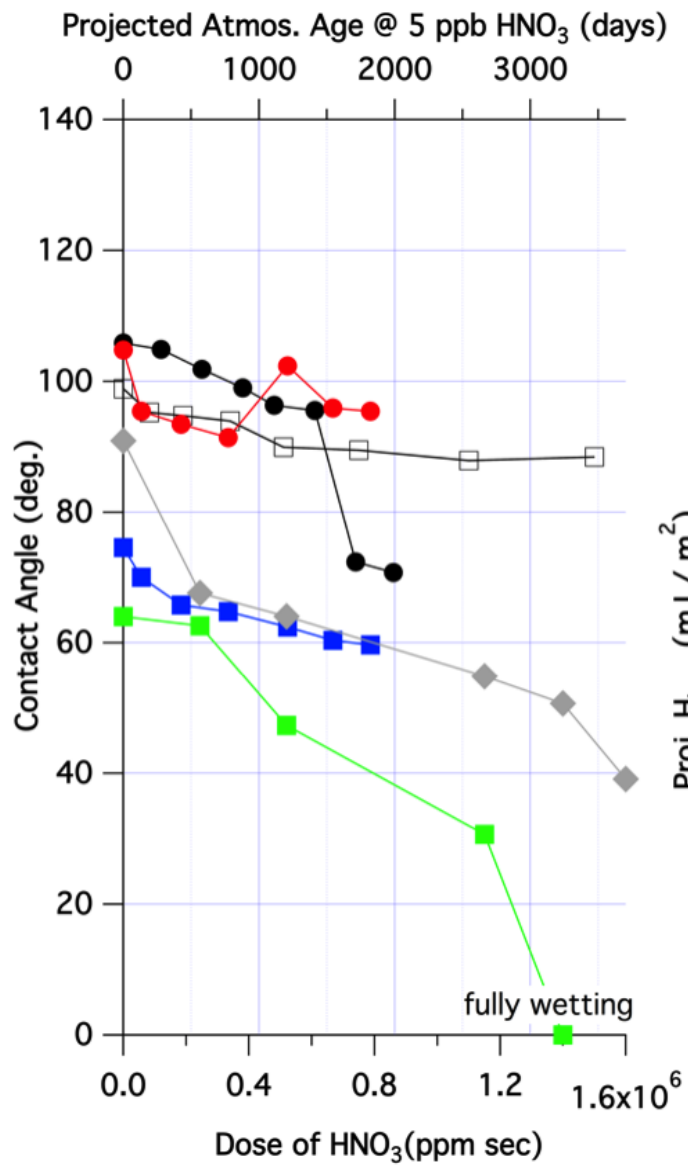

- KEROSENE SOOT

$\square$ FIREPLACE SOOT

- GILLIG BUS SOOT

- NOVA BUS SOOT

$\square \quad$ RTS BUS SOOT

DIESEL ENGINE PARTICLE FILTER

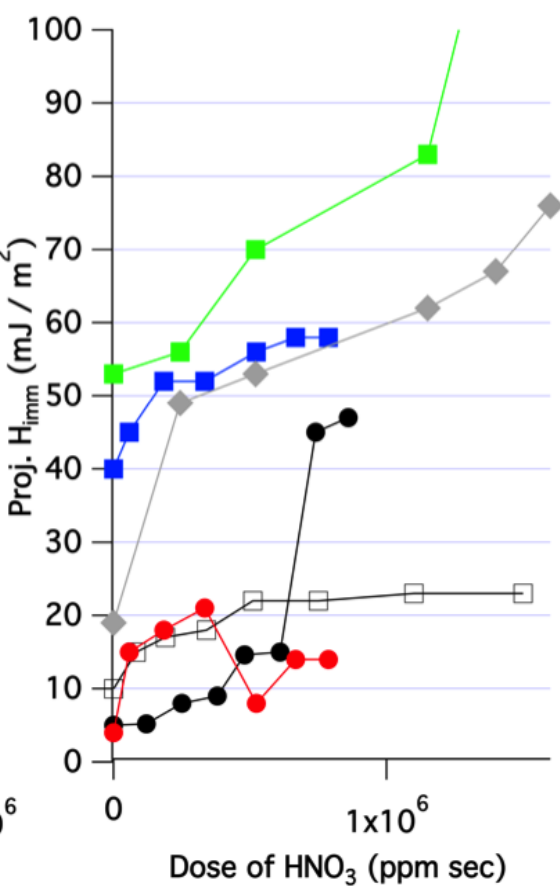

Figure 4. Plots of contact angle and projected $H_{i m m}$ vs. dose of $\mathrm{HNO}_{3}$ vapor applied for several soot samples. Immersion enthalpy was determined through Equation (1). Contact angles often decreased during treatment with $\mathrm{HNO}_{3}$ and $H_{\text {imm }}$ values increased. Results suggest large doses of nitric acid vapor make soot surfaces more hydrophilic. 
of applied dose. As observed, most samples (exception being Gillig bus soot) exhibited a decreased contact angle with extensive nitric acid treatment. Comparing Figure 3 and Figure 4 leads to the conclusion that the nitric acid treatment was, on average, slightly less effective than ozone at increasing the soot wetting. Interestingly, very similar trends were observed between the two chemical treatments. The shape of curves for the Nova bus soot is virtually identical in both figures. The curves for the RTS bus soot and kerosene soot also show similar shapes. Gillig bus soot is largely unresponsive to either chemical treatment. The fireplace soot sample showed the largest difference between treatments-exhibiting a large change in contact angle during ozone processing, but only a moderate change when treated with $\mathrm{HNO}_{3}(\mathrm{~g})$. Another $\mathrm{x}$-axis is added in Figure 4 in an effort to quantitate projected atmospheric age to reaction with $\mathrm{HNO}_{3}(\mathrm{~g})$ at $5 \mathrm{ppb}$ assumed concentration. Again, mega-doses of $\mathrm{HNO}_{3}$ have been used in this experiment, projected to be far greater than what an atmospheric soot particle may experience during its lifetime in the atmosphere. Only very marginal changes in contact angle are observed during the modeled first few hundred days of exposure.

\subsection{Contact Angles for Soot Treated with Sulfuric Acid Vapors}

Another set of experiments investigated whether treating pelletized soot with sulfuric acid vapor affects wetting behavior. In this set of experiments the soot was placed within a sealed dessicator containing $97 \%$ sulfuric acid solution at $20^{\circ} \mathrm{C}-25^{\circ} \mathrm{C}$. The partial pressure of sulfuric acid in the vapor phase used to treat the soot could not be directly measured using technology our laboratory possesses. Because of this, we must estimate the vapor phase concentration through literature reports of the sulfuric acid saturation vapor pressure. W. Roedel [17] reported the vapor pressure above a $99 \%$ solution of sulfuric acid to be about $32 \mathrm{ppbv}\left(2.5 \times 10^{-5}\right.$ torr, at $\left.23^{\circ} \mathrm{C}\right)$ while the work attributed to Perry [15] suggests $17.7 \mathrm{ppbv}$ as the saturation vapor pressure of a $96 \%$ solution at $20^{\circ} \mathrm{C}$. We have adopted the $17.7 \mathrm{ppb}$ estimate since it matches our experimental concentration and temperature conditions. Since atmospheric levels of $\mathrm{H}_{2} \mathrm{SO}_{4}(\mathrm{~g})$ are believed to often be $<10^{7} \mathrm{~cm}^{-3}$ with levels never exceeding $5 \times 10^{7} \mathrm{~cm}^{-3}$ or approx. $2 \mathrm{ppt}$ [18] [19], treating the soot samples with the vapor in equilibrium with the concentrated liquid still represents a very large dose compared to the typical atmospheric case. Figure 5 reports contact angle and $H_{i m m}$ data for various soot samples treated with sulfuric acid vapor. Again, the dose reported should be construed as being very uncertain. While a slight downward trend in the contact angle is noted as applied dose increases, by in large, the sulfuric acid treatment increases hydrophilicity of the soot surface only marginally.

\section{Conclusions}

Treating a variety of soot samples with gas-phase ozone, nitric acid and sulfuric acid almost always reduced the water contact angle and increased the wetting of soot surfaces. However, the very large doses of these reactive gases required to observe significant changes in wetting raises some doubt as to whether the modification of soot surfaces proceeds appreciably via vapor phase atmospheric processing with the substances tested during a typical soot particles lifetime ( $<10$ days). However, alternative chemical 


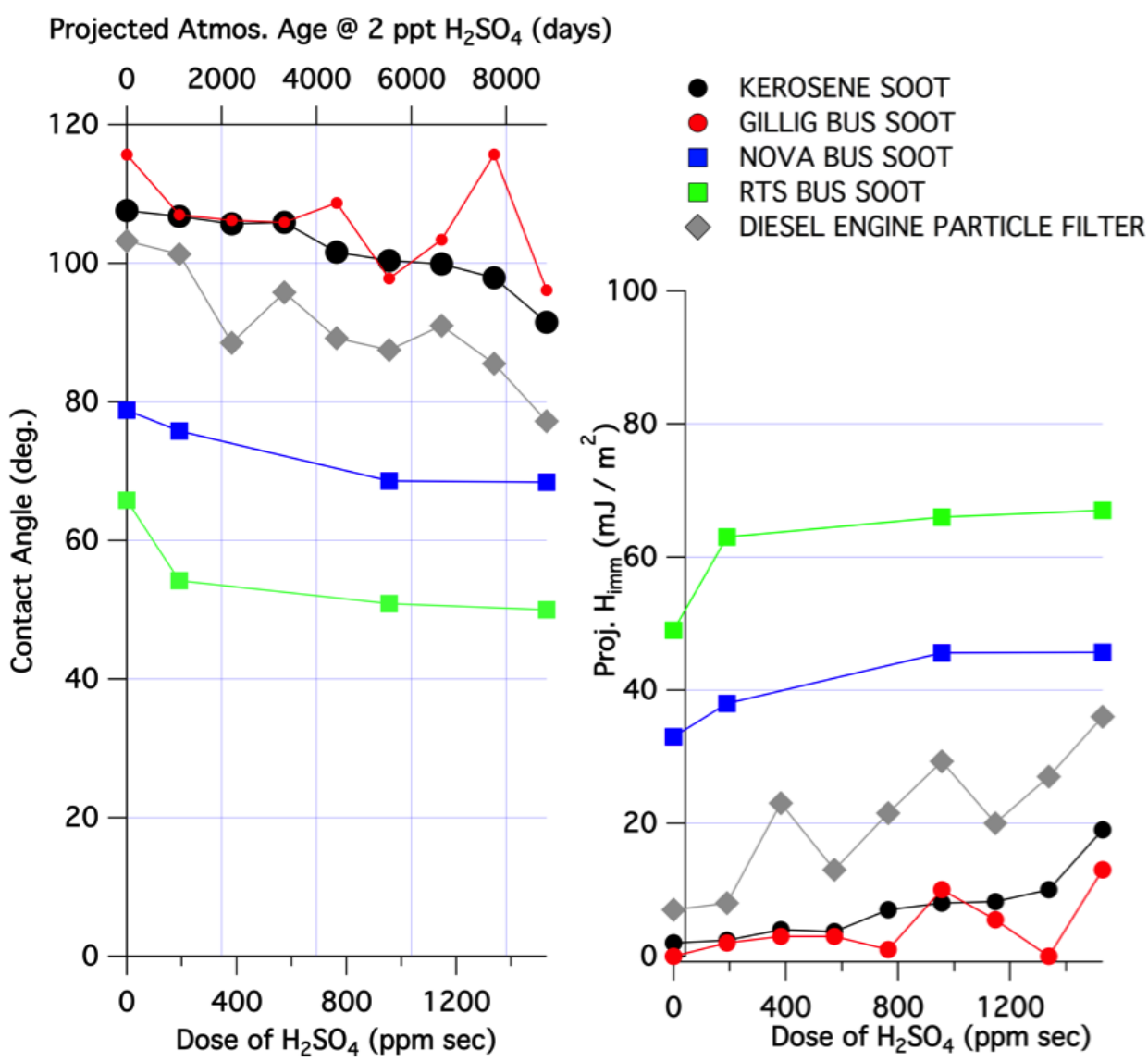

Figure 5. Plots of contact angle and projected $H_{i m m}$ vs. estimated dose of $\mathrm{H}_{2} \mathrm{SO}_{4}$ vapor applied for several soot samples. Immersion enthalpy was determined through Equation (1). Contact angles often decreased during treatment with $\mathrm{H}_{2} \mathrm{SO}_{4}$ and $H_{\text {imm }}$ values increased. Results suggest sulfuric acid vapor makes soot surfaces slightly more hydrophilic. The estimated dose of sulfuric acid vapor should be considered uncertain due to measurement limitations.

mechanisms may exist to modify soot particle surfaces that have not been considered here. In addition, illumination of the soot may play a key role in the process (illumination was not carried out in this study).

One factor that made a large difference in water contact angle was the source of the soot. The municipal bus soot samples exhibited a significant variety of contact angles before chemical treatment from very hydrophobic ( $>90$ deg.) to almost hydrophilic (approx. 60 deg.). Fireplace soot and kerosene lamp soot both proved quite hydrophobic. The variability in contact angle and $H_{\text {imm }}$ observed between soot sources appears to be far greater than what chemical modification with the gas-phase reactants tested can achieve during a typical particle lifetime in the atmosphere. Therefore, the results suggest the surface wetting behavior of soot is largely determined at the source and at the time of emission into the atmosphere. This result may not be terribly surprising. Several authors have previously reported dramatic differences in soot reactivity and microstructure for differing combustion conditions [20] [21] [22] [23]. In addition, Persiantseva et al. [16] observed soot contact angles that varied between $60^{\circ}-80^{\circ}$ depending on source and fuel type. We also clarify that surface wetting/immersion is a different physical phenomenon compared with an internally mixed soot particle accu- 
mulating aqueous phases by virtue of other hygroscopic materials. Finally, contact angle results for the fresh and aged soots are very similar to measurements for graphite and graphene oxide reported in previous literature, so these materials may be good surrogate surfaces for describing soot surface aging/wetting.

Our experiments have several limitations that should be reported. As previously mentioned, the dose of sulfuric acid has been estimated based upon previously reported values of vapor pressure and not measured. As a result, the dose reported within figures is highly uncertain. Next, our experiments did not actively illuminate the soot surfaces with light. When dispersed in Earth's atmosphere, sunlight may influence the surface chemistry of soot and yield more rapid surface modification compared to that which we report within. This could lead to more rapid surface modification reactions. We have also not performed soot pretreatment or chemical analysis on the tested samples, nor have we compressed the soot pellets to a specific, well-controlled pressure prior to contact angle measurements. All of these factors may potentially influence results.

\section{Author Contributions}

Y. W. and Q. Z. performed experiments, reported the data, and proofread/edited the manuscript. J. T. authored/edited the manuscript.

\section{References}

[1] Chylek, P. and Hallett, J. (1992) Enhanced Absorption of Solar Radiation by Cloud Droplets Containing Soot Particles in Their Surface. Quarterly Journal of the Royal Meteorological Society, 118, 167-172. https://doi.org/10.1002/qj.49711850310

[2] Popovicheva, O., Kireevaa, E., Persiantsevaa, N., Khokhlovab, T., Shonijab, N., Tishkovac, V. and Demirdjianc, B. (2008) Effect of Soot on Immersion Freezing of Water and Possible Atmospheric Implications. Atmospheric Research, 90, 326-337. https://doi.org/10.1016/j.atmosres.2008.08.004

[3] Wei, Y., Zhang, Q. and Thompson, J.E. (2013) Atmospheric Black Carbon Can Exhibit Enhanced Light Absorption at High Relative Humidity. Atmospheric Chemistry and Physics, 13, 29413-29445. https://doi.org/10.5194/acpd-13-29413-2013

[4] Spagnolo, D.A., Maham, Y. and Chuang, K.T. (1996) Calculation of Contact Angle for Hydrophobic Powders Using Heat of Immersion Data. The Journal of Physical Chemistry, 100, 6626-6630. https://doi.org/10.1021/jp951405m

[5] Bradley, R.H., Sutherland, I. and Sheng, E. (1995) Relationship between Carbon Black Surface Chemistry and Energy. Journal of the Chemical Society, Faraday Transactions, 91, 3201-3207. https://doi.org/10.1039/ft9959103201

[6] Kraus, G. (1955) The Heat of Immersion of Carbon Black in Water, Methanol, and nHexane. The Journal of Physical Chemistry, 59, 343-345. https://doi.org/10.1021/j150526a016

[7] Rodriguez-Reinoso, F., Molina-Sabio, M. and Gonzalez, M.T. (1997) Effect of Oxygen Surface Groups on the Immersion Enthalpy of Activated Carbons in Liquids of Different Polarity. Langmuir, 13, 2354-2358. https://doi.org/10.1021/la961047u

[8] Young, G.J., Chessick, J.J., Healey, F.H. and Zettlemoyer, A.C. (1954) Thermodynamics of the Adsorption of Water on Graphon from Heats of Immersion and Adsorption Data. The Journal of Physical Chemistry, 58, 313. https://doi.org/10.1021/j150514a006

[9] Wang, Z.B., Hu, M., Mogensen, D., Yue, D.L., Zheng, J., Zhang, R.Y., Liu, Y., Yuan, B., Li, X., Shao, M., Zhou, L., Wu, Z. J., Wiedensohler, A. and Boy, M. (2013) The Simulations of 
Sulfuric Acid Concentration and New Particle Formation in an Urban Atmosphere in China. Atmospheric Chemistry and Physics, 13, 11157-11167.

https://doi.org/10.5194/acp-13-11157-2013

[10] Dreyer, D.R., Park, S., Bielawski, C.W. and Ruoff, R.S. (2010) The Chemistry of Graphene Oxide. Chemical Society Reviews, 39, 228-240. https://doi.org/10.1039/B917103G

[11] Liu, Y., Liu, C., Ma, J., Ma, Q. and He, H. (2010) Structural and Hygroscopic Changes of Soot during Heterogeneous Reaction with $\mathrm{O}_{3}$. Physical Chemistry Chemical Physics, 12, 10896-10903. https://doi.org/10.1039/c0cp00402b

[12] Wei, Y., Ma, L., Cao, T., Zhang, Q., Wu, J., Buseck, P.R. and Thompson, J.E. (2013) Light Scattering and Extinction Measurements Combined with Laser-Induced Incandescence for the Real-Time Determination of Soot Mass Absorption Cross Section. Analytical Chemistry, 85, 9181-9188. https://doi.org/10.1021/ac401901b

[13] Friedel, R.A., Shultz, J.L. and Sharkey, A.G. (1959) Mass Spectrum of Nitric Acid. Analytical Chemistry, 31, 1128-1128. https://doi.org/10.1021/ac60150a615

[14] Taylor, G.T. (1925) Vapor Pressure of Aqueous Solutions of Nitric Acids. Industrial \& Engineering Chemistry, 17, 633-635. https://doi.org/10.1021/ie50186a037

[15] Perry, R.H. (2008) Perry's Chemical Engineers' Handbook. 8th Edition, McGraw-Hill, New York, 2-86.

[16] Persiantseva, N.M., Popovicheva, O.B. and Shonija, N.K. (2004) Wetting and Hydration of Insoluble Soot Particles in the Upper Troposphere. Journal of Environmental Monitoring, 6, 939-945. http://dx.doi.org/10.1039/b407770a

[17] Roedel, W. (1979) Measurement of Sulfuric Acid Saturation Vapor Pressure; Implications for Aerosol Formation by Heteromolecular Nucleation. Journal of Aerosol Science, 10, 375 386. http://dx.doi.org/10.1016/0021-8502(79)90032-6

[18] Wang, S., Zhang, Y., Abidi, N. and Cabrales, L. (2009) Wettability and Surface Free Energy of Graphene Films. Langmuir, 25, 11078-11081. http://dx.doi.org/10.1021/la901402f

[19] Weber, R.J., McMurry, P.H., Mauldin III, R.L., Tanner, D.J., Eisele, F.L., Clarke, A.D. and Kapustin, V.N. (1999) New Particle Formation in the Remote Troposphere: A Comparison of Observations at Various Sites. Geophysical Research Letters, 26, 307-310. http://dx.doi.org/10.1029/1998GL900308

[20] Al-Qurashi, K. and Boehman, A.L. (2008) Impact of Exhaust Gas Recirculation (EGR) on the Oxidative Reactivity of Diesel Engine Soot. Combustion and Flame, 155, 675-695. http://dx.doi.org/10.1016/j.combustflame.2008.06.002

[21] Al-Qurashi, K., Zhang, Y. and Boehman, A.L. (2012) Impact of Intake $\mathrm{CO}_{2}$ Addition and Exhaust Gas Recirculation on $\mathrm{NO}_{\mathrm{x}}$ Emissions and Soot Reactivity in a Common Rail Diesel Engine. Energy \& Fuels, 26, 6098-6105. http://dx.doi.org/10.1021/ef201120f

[22] Song, J., Alam, M. and Boehman, A.L. (2007) Impact of Alternative Fuels on Soot Properties and DPF Regeneration. Combustion Science and Technology, 179, 1991-2037. http://dx.doi.org/10.1080/00102200701386099

[23] Vander Wal, R.L., Yezerets, A., Currier, N.W., Kim, D.H. and Wang, C.M. (2007) HRTEM Study of Diesel Soot Collected from Diesel Particulate Filters. Carbon, 45, 70-77. http://dx.doi.org/10.1016/j.carbon.2006.08.005 
Submit or recommend next manuscript to SCIRP and we will provide best service for you:

Accepting pre-submission inquiries through Email, Facebook, LinkedIn, Twitter, etc. A wide selection of journals (inclusive of 9 subjects, more than 200 journals) Providing 24-hour high-quality service

User-friendly online submission system

Fair and swift peer-review system

Efficient typesetting and proofreading procedure

Display of the result of downloads and visits, as well as the number of cited articles Maximum dissemination of your research work

Submit your manuscript at: http://papersubmission.scirp.org/

Or contact acs@scirp.org 